\title{
Bollywood's variation on the firanginess theme: Song-and-dance sequences as heterotopic offbeats
}

\section{Monia Acciari}

\section{De Montfort University}

\begin{abstract}
Song-and-dance sequences have widely been studied as disruptive elements in the narrative of popular Hindi cinema and as quintessential traits of this industry. While the utopic dimension of such musical intervals has largely been theorised, the aim of this article is to expand on this framework to articulate the heterotopic dimension of these interludes. Foucault's concept of heterotopia allows further study of how song-and-dance sequences are elements responsible for communicating both social and cultural aspects. On a similar note, it must be mentioned that the use and representation of foreigners in Indian cinema dates back to its origins, when foreign actresses were often employed in films, replacing local performers. Through historical exploration, this paper will specifically investigate how song-and-dance sequences are important 'malleable elements' of the narrative, which are able to articulate identity and to discourse on the representation and articulation of firanginess in popular Hindi cinema.
\end{abstract}

\section{Keywords}

Bollywood, Firanginess, Foreignness, Song and dance sequences, Heterotopic spaces.

The history of the fascination that Indian cinema productions have with foreign bodies and cultures dates back to the very beginning of Indian cinema, when mostly British-Jewish and Indo-American actresses populated the silent screens of India, conveying a deeply international flavour right from the start. When it comes to engaging with the history of songand-dance sequences and the role these 'interruptions' (Gopalan 18) have played in depicting firanginess (foreignness) in popular Hindi cinema, the 1950s and 1960s established an important trend. Song-and-dance sequences from that era viewed the appearance of foreign 
and non-Indian bodies as a means of providing a marked contrast with the heroine of the films and, as such, as simply a representation of racial and cultural 'otherness'; this characteristic was often used to distinguish social values of appropriateness and unsuitableness, as will be discussed further. Often song-and-dance sequences - natural intervals within the melodramatic story of popular Hindi films - have been used as extraneous interludes that were alien to the development of the narrative, and hence foreign to the plot. This work intends to explore, via filmic text analysis, how song-and-dance routines, which punctuated the narrative of these films as the unaccented offbeats of secondary importance, have evolved over time. In addition, it is important to examine how such musical instances further the representation of firanginess ${ }^{1}$ in Bollywood cinema; this article proposes an essential historical overview of this phenomenon. ${ }^{2}$

By looking at the past and more recent history of the representation of foreignness in popular Hindi cinema, this work will delineate a trend in the transformation of the representation of firangi and the filmic function these narrative instances fulfil in constructing and problematizing the identity of the firangi. This started in the 1950s, with the firangi as a fetishised transgressive vamp, then progressed in the 1960s to the creation of the 'masked type' form of firanginess, and more recently saw the emergence of the redemption-seeking firangi type. ${ }^{3}$ The aim is to address the socio-cultural responsibility held by song-and-dance sequences to update the representation of firanginess in popular Hindi cinema. Beginning with a historical overview of salient song-and-dance sequences characterised by their contribution to the notion of foreigner and foreignness over time, the final part of this article will go on to evaluate more contemporary Bollywood songs-and-dances and the current rehabilitation of foreign bodies within the main narrative of the films. I also seek to establish which aspects of foreignness are pronounced and which are suppressed by song-and-dance sequences in recent Bollywood films, to further observe images of 'tailored' foreignness. I 
will engage with theoretical notions of human geography and specifically with the idea of Michel Foucault's heterotopia alongside filmic text analysis, in order to explore the tension between 'domesticity' and transnationalism in these musical interludes.

By looking at heterotopia, the idea is to address the cultural position these filmic moments occupy, in light of the theoretical support that Foucault's notion offers; heterotopic spaces are defined by the author as 'other spaces' where individuals have little or no intelligible connection with the larger context in which these spaces exist (Foucault 'Of Other Spaces' 25). This notion thus upgrades our interpretation of song-and-dance sequences as merely spaces of desire, to an understanding of them as spaces where firanginess is presented more conspicuously. Such an approach seeks to add another layer of complexity to what Sangita Gopal and Sujata Moorti write about such musical intervals. Song-and-dance sequences are socio-political realities and aesthetic experimentation in between realism and utopia (Gopal and Moorti 5). In this light, this article wishes to respond to the following research questions: How have song-and-dance sequences presented the idea of firangi across time? Are song-and-dance sequences instances within the narrative that are capable of articulating and feeding specific negative stereotypes while unpacking our understanding of firanginess in Bollywood films? To answer these questions, I will be looking at specific song-and-dance performances from the 1950s and 1960s that best typify representation of firanginess. By looking at the song-and-dance routine in popular Hindi cinema, the aim is to explore the evolution of these melodic spaces as subversive interventions that enable the representation of firangiyon (foreigners) in the filmic text.

\section{Variations on the theme of firanginess: initial annotations}

The mingling of traditional traits with the flavour of other international aspects has heavily influenced popular Hindi films and the song-and-dance sequences within them (Gopal and 
Moorti 4). As Sangita Shresthova reminds us, the use of songs and dances as narrative tools to communicate instances of untold stories and sentiments is part of Bollywood's worldwide appeal (6). The fame of songs working independently from the films they originate in, and their transformation and re-appropriation into broader social contexts as part of discourses on fandom activism (Jenkins and Shresthova), have seen these narrative tools span beyond the film texts themselves and have enabled them to pervade other socio-cultural dimensions even beyond the boundaries of India. It is because of this fragmentation - the partial detachment from the original filmic text and shift into new contexts and forms - that these song-anddance sequences are characterised as having 'ubiquitous dispositions' (Gopal and Moorti 2). Much in the same spirit, Jayson Beaster-Jones writes, specifically with reference to Bollywood songs, that such instances are 'written for moments in the narrative that communicate a complex of musical and extra-musical information' (35). My intervention in this field aims to deepen the understanding of the malleability inherent in these musical intervals, at a cultural level. Hence, the films that have been selected for the analysis in this article matter for three reasons. Firstly, they are recognisable texts, which are important as they testify distinct historical moments in the evolution of song-and-dance sequences in popular Hindi cinema. Secondly, they demonstrate how song-and-dance sequences have a specific function within the narrative of the film. Thirdly, they go beyond the common understanding of song-and-dance sequences as moment of escapism and serve to highlight the filmic function they have in defining foreignness. As such this article will use four films as case studies, to construct and problematise the identity of the foreigner. The films are Howrah Bridge (1958), Gumnaam (1965), Love Aaj Kal (2009) and Rang de Basanti (2006). It is therefore important to think about song-and-dance sequences as responsible elements that are able to inform multiple dimensions of a culture and formulate, through an analysis of gestures and movements, the semantics of a society in which modernity and tradition often 
clash. I suggest that song-and-dance sequences should be regarded as germinal spaces and important 'malleable elements' of a Bollywood film able to instigate new discourses on representation and articulations of firanginess.

In an article on Bollywood cinema and its relationship with the West, and the representation of the 'other', Vinay Lal (1998) describes the impossibility for 'outsiders' what I am framing here as firangi - to be an integral part of modern Hindi films; Lal writes:

There has never been any true outsider in the commercial Hindi film, although as the demands of the ethos of the Indian nation continue to supersede the ethos of Indian civilization, and the boundaries of inclusivity continue to shrink, the outsider will finally have found a place in Indian society. If and when the popular Hindi cinema shows a keen awareness of the outsider, and gives the notion of the 'other' an ontological sanctity, we shall have irreversible proof that in India as in the underdeveloped West...the project of modernity has been, in this most resilient of civilizations, rendered complete.

However, the problem that Lal's work presents is that of the generalisation of the notion of the foreigner, which lends itself to a more detailed study of the subject. The author explores otherness across diverse films, providing a rather broad idea of the foreigner - pictorialised as the 'universal other' - which does not take into account the geographical, cultural, historical and social connotations of a foreign body. In this light, the objective of my work is, along with expanding the body of literature on this subject, to call for a break from the generalised view of the West and the foreign as the ultimate 'other', which song-and-dance sequences have conveyed until now. This work aims to reappraise the existing argument on the representation of 'otherness' (Kishore, Savwal and Patra) in Indian cinema. Beyond this, it will also move beyond the confines of a dualistic approach - realism or utopia - that framed song-and-dance sequences historically. In this regard I will propose a third framework for the understanding of these sequences, in order to propose a third dimension: the heterotopic. The aim is to encourage the reading of foreign specificities, overtaking generalisation. In doing 
so, the intention is to propose a wider critical appreciation of firanginess through the study of its evolution across a variety of song-and-dance sequences. These musical instances within the narrative of the film need to be studied as the filmic components able to shape representations of foreignness in popular Hindi cinema. In order to formulate a renewed frame of interpretation of the filmic index of changing representation of firangi, I propose to theoretically engage with the notion of heterotopic spaces, articulated by Foucault.

\section{Heterotopia: the spaces of crisis}

Heterotopia is a notion elaborated by French philosopher Michel Foucault that is largely applied to the discipline of human geography. The prefix 'hetero' from the Greek word héteros (meaning other, another and different) is joined with the term 'topia' (meaning spaces); this produces the meaning of 'other space'. Heterotopia is a space where things are different, a space within which individuals exist but have little or no comprehensible connection with one another. The French philosopher used the term to talk about spaces belonging to the human experience that exists outside of utopian and dystopian dimensions. Heterotopian spaces are described as being gaps where otherness exists, and functions at physical, psychological and social levels (Foucault, The Order of Things; Foucault and Miskowiec). The examples that Foucault proposes are the moment of a phone call or our experience of looking at ourselves in the mirror, writing further that,

The mirror functions as a heterotopia... it makes this space that I occupy at the moment when I look at myself in the glass at once absolutely real, connected with all the space that surrounds it, and absolutely unreal, since in order to be perceived, it has to pass through this virtual point which is over there.

(Foucault, 'Of Other Spaces’ 232)

Such an account formulates a complex way of thinking about what is real, and of distinguishing between what is unreal or utopic and what is perceived and accepted. 
A space, Foucault explains, plays an important role in framing the presence that bodies have within a specific context and thus the social and cultural value they have in it ('Of Other Spaces' 238). Foucault, defines categories of heterotopia to place these human aspects into perspective. The author highlights that we are still exposed to specific oppositions and defined boundaries, producing a multitude of meanings; such meanings are defined by both the 'bodies' inhabiting these spaces and by their mutual relationship with the overall context. Within the broader discourse that engages with the performance of foreignness in song-anddance sequences within and beyond Bollywood films, some of these boundaries need to be reviewed. In the process of decoding the 'foreignness' within the diegetic spaces of song-anddance sequences in popular Hindi films, the interpreting becomes a complex process of cultural reassessment. In order to study such a new relationship, it is important to look at how heterotopias, and broadly heterotopian spaces (which are here referred to as spaces of the song-and-dance sequences within which foreign bodies exist), are able to inform the dynamics of identity formation.

Heterotopia, Foucault reminds us, is a real place, which branches out from a known space (Foucault and Miskowiec 24). Within this frame, sites such as a zoo are examples of heterotopias, as these spaces assemble 'bodies' that are not usually found together. In this article, the spaces of songs and dances, wherein foreignness is embedded, are to be read within the theoretical frame of heterotopia, that is, the moment when foreignness is 'allowed' and even accepted as part of what I would like to dub here 'spaces of crisis'. Song-and-dance sequences are not only moments that break the linearity of the narrative, or insertions of dream-like moments; these sections of the films are also moments of transgression that are suspended and discontinuous from the story. Examples of such transgressive moments are the strategically placed item numbers featuring 'item girls', who were provocative and often foreign. The foreign item girls were used to create an opposition with the idealised moral 
universe evoked by the plot of the film, and to arouse erotic pleasure on the part of the target audience (Kishore 145). Hence, these interruptions should be studied as spaces of rupture within the narrative, where traditional moral codes are in crisis. Within these set parameters, it is worth interrogating the existence of foreign bodies within popular Hindi films, specifically looking at how such bodies (with their non-Indian traits) are enabled to perform their foreignness.

In 'Of Other Spaces', Foucault argues that heterotopic spaces, in their natural and unusual relationships with other places, suspend, neutralise and reverse the relationships that a particular space has established and constructed with a body and the certain knowledge of the context to which that body originally belongs. Thus, in light of such spatial functions, it is important to evaluate the representation of foreignness transmitted through song-and-dance sequences to observe the historical shift and the cultural signification that these bodies have acquired over time.

Song-and-dance sequences within Bollywood films are observed in this article as borderline spaces in which heterotopias of crisis and deviation form a space of suspension and redefinition of human possibilities and acceptability. Within this theoretical frame, songand-dance sequences such as 'Mera Naam Chin Chin Chu' in Howrah Bridge, 'Jaan Pehechaan Ho' in Gumnaam, 'Masti Ki Paathshala' and 'Khalbali' in Rang de Basanti and 'Twist' in Love Aaj Kal function as germinal spaces in which the evolution of representations of firanginess in popular Hindi cinema can be re-read.

\section{From exotic Helen to 'twisting' blondes: the dancing firangi bodies}

The use of foreign bodies in Indian cinema to depict heroines, who would present a different kind of personality from the positive, moral rectitude of Indian women, dates back to the origins of this cinema (Acciari, 'Theorizing Liminal Cinema'; Gehlawat; Thomas). After the independence of India, rather than liberalising film censorship, the newly reconstituted 
Central Board of Film Censors (now Central Board of Film Certification) tightened the control on what should be seen and accepted (Mishra 184). Post-independence, the nationalist project worked to create a unique and renewed Indian identity that by moving away from the colonial past, sought to uphold tradition and morality (Kishore). The industry was faced with emergent representational strategies that would see women being used as positive role models, without sacrificing other pleasures for the audience (Devasundaram 49). With the aim of upholding traditional values via the use of women as symbols of the nation, the Hindi film industry began deploying foreign characters who would provide a contrast with the Hindi heroines and clash with the notion of the woman as muse; this character was the vamp often represented by over-westernised women or non-Indian actresses. It is in the paradigmatic moment of song-and-dance sequences that the performance of foreign bodies contrasts most markedly with those of the Indian heroines. While for the heroine, the songand-dance sequences were tailored to be integrated and legitimised in the narrative of the film, the foreign bodies were often items of crude entertainment distant from the syntagmatic narrative. In such a display, the disposable bodies of the foreigners had the central purpose of soliciting and intensifying voyeurism. As analysed further, song-and-dance sequences, which employed foreign actresses, led to the emergence of a specific representation and decoding of the West and the production of a series of characteristics that have formed a potential archive of knowledge on firanginess.

The most prominent of the firangi bodies of the 1950s and 1960s that needs to be remembered here as being crucial to the evolution of firanginess is the 'flirtatious' Helen, who appeared as an item dancer in numerous Bollywood films. Helen, trained as a cabaret dancer and of Franco-Burmese descent, was defined as the temptress and exotic item dancer contrasting with the positive image of Indian women in the films of this period and throughout the 1970s (Pinto 7-10). Among the notorious song-and-dance sequences that 
remain connected to Helen is 'Mera Naam Chin Chin Chu' in the film Howrah Bridge (1958), which illustrates the eclecticism of a woman who defied the rules of gender in an era when the Bollywood scene was dominated by Raj Kapoor, Dev Anand and Dilip Kumar and, in the 70s, by Amitabh Bachchan. The film is a concoction of mystery and suspense that sees Ashok Kumar as Prem determined to recuperate the family jewels and bring the killers of his brother to justice. The action is interspersed with songs that include an element of attraction and sub-plots (Vasudevan) that break up the narrative and introduce new narratives, which, Lalitha Gopalan claims, constitute a system of interruption. Gopalan argues in fact that 'the most persistent narrative form found in Indian popular cinema includes several interruptions bearing a more or less systematic relationship to the narrative' (19).

In the 'Mera Naam Chin Chin Chu' song-and-dance sequence Helen moves through a variety of looks that range from the perfect East-Asian lady wrapped in a fitted cheongsam to a Western woman in a sailor dress, thus showcasing and outlining a variety of identities that define a new set of traits of foreignness. The sequence starts with four men dancing and playing with a small ball; Helen, dressed in an East-Asian outfit, dancing and snapping her fingers, runs down the stairs to join the playful group. This early image is cut with other dancing East-Asian ladies within a context that has the flavour of post-war indulgence. Helen, with a series of vibrant and hopping steps, changes partners before falling into the arms of one of them, only to finally shy away from him again. Helen moves fluidly across the scene, bouncing between the arms of her various male partners, openly declaring noncommitment.

In a frenetic and whirling final moment, Helen completes her dance in the arms of various partners, between whom she moves intermittently; the game of taking a partner and leaving him builds up a sense of desire and inaccessibility that occurs only within the brackets of a song-and-dance sequence; desire is otherwise unrepresented and improbable 
within the main narrative of the film. This song-and-dance sequence is composed of a series of gestures, foreign aesthetic features and compositional steps that form, through the interaction of the dancing bodies, a dialect of acceptance and rejection, of closeness and distance that powerfully layers the image of the foreigner in Bollywood cinema. The creation of such an archive of gestures and attributes clashes with the compass of the moral universe that the heroine of the film normally embodies, in which an idealised identity of the nation is underpinned by a fetishisation of chastity. In this light, it should be remembered that these kinds of song-and-dance sequences are arbitrarily inserted and stitched together within the main narrative of the film, but resolve and propel the narrative in crucial ways (Gopalan 67). Helen's vamp persona lends to the reading of foreignness as an (in)accessible body; she is accepted within the body of the filmic text but detached from the actual narrative, thus becoming an accessory item. This image is constructed through the continuous borrowing and re-adaptation of material from non-Indian vocabularies of gesture and expression in Bollywood films.

The borrowing and re-working of Western gestures into popular Hindi cinema were developed further in the 1960s. The culture of 'club songs' has produced an emblematic and problematic representation of the foreigner. While a recognised definition still needs to be formalised and codified, the 'club song' genre finds its climax in 'Jaan Pehechaan Ho' in Gumnaam (1965). While being interpreted by the Indian performer Laxmi Chhaya, the song strongly refers to the swinging London of the 1960s and American club culture. The dancers, who are wearing Western-style clothes, gyrate frenetically at the centre of the room, creating a spectacle of Western youth culture. While other song-and-dance sequences are usually sonorous interpolations with recognisable Indian beats and narrative function, the 'offbeat' club songs here are suspended from the narrative, offering no commentary on the characters or storyline. The club songs, while acknowledging the musical youth culture of the 1960 s, 
also created imaginative access to fantasies of the West, in which a specific definition of the foreigner is embedded: that of perdition, liberalisation and transgression. The representation of the foreigner in the 1960s appears to change in form: Indians now wear a mask to achieve a certain degree of foreignness and transgression; however, foreignness is still presented with specific connotations - that of the negative firangi (Harris) and the vamp. 'Jaan Pehechaan Ho' is set in a club and, when the doors open, the audience is taken from the outside world into the foreign, permissive world inside the club. The camera moves towards a group of masked men and then moves towards a masked girl in a golden lamé dress, with an aesthetic reminiscent of the 1960s. The frenetic sounds of the drums, guitars and brass ensemble match the dancers' syncopated movements, who sway to the beat of Westernised music. Masked and unrecognisable, the Westernised bodies in the film are not only deprived of an identity but they are also confined to the underground club: a space and world that is in itself alien and foreign. 'Jaan Pehechaan Ho' does not fully serve the purpose of the narrative of the film, but it is able to build a suspended - heterotopic - moment, where the bearers of foreignness are updated from being represented as vamps and seducers, to being empty and anonymous presences extraneous to the narrative. The song produces a variation of the image of the foreign - the masked type - through the Westernisation of the performance. The costumes, the black masks the dancers use to obscure their identity, and the presence of the band Ted Lyons and his Cubs - an Indo-American band that played in some 1960s Bollywood films and was inspired by the Beatles - all make for a performance of the foreign West.

While films of the 1950s and 1960s have offered the opportunity to reflect on the strategies used to represent firangi bodies with specific negative connotations, the exploration of more recent films will reveal how such representations have evolved. In addition, the idea is to look at what happens when the firangi elements are placed within the narrative of the film, and how the role of song-and-dance sequences is transformed in such a scenario. While 
the 1950s and 1960s have offered a model of firangi representation, more recent films have provided an opportunity to explore other representations of the same phenomenon. An example of a more recent representation of firangi bodies in Bollywood cinema is proffered by the film Love Aaj Kal (Imtiaz Ali, 2009), an Indian romantic comedy starring Saif Ali Khan as Jai, Deepika Padukone as Meera and English model Florence Brudenell-Bruce impersonating Jo. The film presents a love triangle that sees Jai living in London with Meera. They are a happy couple; however, believing in different values the couple split, and while Meera returns to India and to her former Indian love Vikram (played by Rahul Khanna), Jai remains in London to later pursue his American Dream and move to San Francisco to find employment in the city. Once in the US, he begins dating Jo, a blonde, foreign woman whom he meets in a disco. The song entitled 'Twist', during which the protagonist is invited by an African-American man to join a party that is redolent of an urban burlesque setting show, is the moment when Jo and Jai meet. Reaching the disco-club, the music is irrepressible and young dancers from mixed ethnic backgrounds dance to the rhythm of 'Twist'. Invited by one of the girls of the dance troupe, Jai begins dancing among a large group of Western women, twisting and imitating the movements of the dancers. The camera moves into a nightclub, where a man dressed as a magician and a few women wearing blonde wigs and sequinned black dresses look at Khan mischievously. Heading towards a balcony in the disco-club, he is seen looking at the crowd, while a close up of Jo with a glass in her hand reveals her character approaching the dancing mob. The two protagonists' eyes meet and, in an energetic dance, they rejoice to 'twist' together. Jo walks away and meets Jai in a dark room but, once they are together, she runs away again, building once more a dialectic of attraction and rejection, of accessibility and dismissal. It is only in the darkness of the room that their bodies touch and they look passionately into each other's eyes. This confines a series of flirtatious moments to the context of the dance; since the space remains that of the disco-club, the love 
between Jo and Jai has sprung up in a context of excess and transgression. Evading the possibility of a kiss, Jo breaks away from their passionate embrace at the edge of the club's balcony and runs away again, only to be recaptured and held to dance and twist again with him. The song's lyrics continue:

\author{
Sone Mone Malla Malli Kar Gaye Talli Aankh Waank \\ Se Lad Gayi, Haan Lad Gayi \\ Bottle Shottle Kholi Bina \\ Daaru Shaaru Bin Peethe Hi \\ Chad Gayi, Haan Chad Gayi \\ (Beautiful woman, let me drink with her eyes \\ She's hooked me, yes I'm hooked \\ The bottle, without opening it \\ The wine, without drinking it, \\ I'm still drunk) $)^{4}$
}

While everyone is dancing and moving, the couple meet and become intoxicated by one another. Following a few more energetic moments and a range of people twisting their bodies through dance and acrobatics, the couple stops and walks away from the crowd, hinting at the need for intimacy and solitude. The song 'Twist' is an important moment of reflection on the representation of foreignness. Twist suggests a moment of transgression that moves away from the conventions of a linear life and love encounter; Jai and Jo meet in the darkness of a disco-club - a twist on the convention of courtship in traditional Bollywood cinema, but evidence of an increased permissiveness since 2000. The selection of the Twist as a melodic and dancing style recalls the 1959 American style - the Twist - that historically was understood to be provocative, audacious and rebellious (Knowles). 'Twist' in Love Aaj Kal recreates the spirit of rebellion that permeated the $60 \mathrm{~s}$ as well as a degree of nostalgia for those times. The convergence of these cultural elements bonds the representation of Jo to the 
well-established grammar of the foreigner; the song-and-dance sequence in 'Twist' adds, literally, a twist to the boy-meets-girl dynamics, where the love story begins in the dark, underground setting of the disco-club. The blonde seducer of dubious morals is later unable to belong firmly to the narrative of the film as a legitimate and accepted body (Kishore); the relationship between Jo and Jai is a forbidden relationship - Jai will return to Meera later in the story - and their relationship is shrouded in the darkness and dubious morality of a nightclub. Although Jo is embedded within the narrative to a greater extent than one might have expected of a firangi in the 1950s and 1960s, happiness is beyond her reach. Though the representation of firanginess might have come some distance, such characters are still prevented from being fully integrated. This is reinforced by the fact that Jo's song-and-dance routines are most frequently located in a nightclub setting, which is itself reminiscent of the type of locations in which firangi characters would be most often found in the 1960s.

While the firanginess of Jo is now included within the story, and yet connected to the representations of the 1960s, a further variation on the theme of how song-and-dance sequences produce a pattern of representation on firanginess is seen in Rang de Basanti (2006). The plot narrates the story of British firangi Sue (Alice Patten), a filmmaker who moves to India to produce a documentary based on her grandfather's diary on Indian freedom fighters. In India, she meets a few new friends and the university student 'DJ' (Aamir Khan). Blonde-haired and blue-eyed, Sue falls in love with DJ, but their love, which includes premarital sex and passion, soon comes to an end without 'naturally' transforming this liaison into a recognised and socially accepted engagement. This becomes evident during some of the song-and-dance sequences. In one such sequence, Sue and DJ dance to the lyrics of 'Masti Ki Paathshala' whilst on a night out on a university campus. The song lyrics issue an invitation to be a rebel, to transgress the boundaries of a life made up of duties and rules. While there is a duality to University life, in that these institutions could be seen either as 
spaces of order or of youthful experimentations, it is the latter that is emphasised here. The lyrics 'Apni toh paathshala masti ki paathshala', which translates as 'our school is a school of fun', suggests a subversive spirit, which is also evident in the final lyric that calls on the students to 'lose control'. This invitation to let go of the prefixed rules of society provides the perfect backdrop to the flirtation between DJ and Sue, who is lured by his personality. The song's lyrics run:

\author{
Chehre ki kitaabein hai \\ Hum woh padhne aate hai \\ Yeh surat teri meri \\ Mobile library \\ Yaaron ki equation hai \\ Love multiplication hai \\ Jisne dilko jeeta hai \\ Woh alpha hai theta hai (x3) \\ (We come here to read the faces \\ Which are books for us \\ The face of you and me \\ A mobile library \\ There is equation of friends \\ Where love is multiplied \\ The one who has won the heart \\ That is alpha and theta. $)^{5}$
}

DJ looks at Sue and invites her to join him in a dance that is punctuated by sexually explicit gestures of pleasure and that articulates a performance of their feelings and their vulnerable relationship. This type of public acknowledgement of sexuality clashes with the norms of representation in traditional Bollywood cinema and underlines the extent to which 
their interracial relationship steps beyond the conventions of Indian society. Far from being a melodramatic and escapist moment of visual pleasure, as other authors have argued (Gopal and Moorti; Sen) of similar melodic intervals in comparable films, this sequence instead stresses the possibility for rupture that song-and-dance intervals offer within the main narrative of the film. The sexualised transgression of DJ and Sue are not set aside to allow for the spectacle of the dance but instead are underscored by both the lyrics and the performances.

Sue clearly forges for herself a unique place as a firangi woman within the landscape of contemporary Bollywood. She is embedded within the narrative in a way that was impossible in the 1950s and 1960s. Unlike Jo in Love Aaj Kal, she achieves a level of acceptance within DJ's family but does not surrender her disruptive potential or her agency. In this sense, she represents something new and can be thought of as the ultimate evolution of the firangi, operating within, whilst also unsettling traditional Indian society.

However, despite these accomplishments she is still denied her happy ending and, as with Jo, ultimately remains an outsider. DJ dies at the radio station as a martyr for the nation, while Sue is prevented by a human barrier from reaching him. She is deprived of the possibility of saving him, loving him or dying with him. This clearly reasserts the position occupied by foreign bodies in popular Hindi cinema, that of denial by traditional society. This does not undo the film's early work in differentiating her from the predecessors of the 1950s and 1960s, it is important to note that foreign bodies are still exiled from the main narrative of the film.

During the aforementioned songs from Rang de Basanti, the friends in the group hardly acknowledge DJ and Sue; the couple is left to 'multiply their love' - 'Love multiplication hai' - creating space within these filmic musical instances for their love to blossom. Song-and-dance sequences are heterotopic spaces and a metaphorical cocoon of 
foreignness, within which, in this case, DJ and Sue's relationship - an interracial liaison - has the opportunity to exist. DJ dances around Sue who, standing immobile, is wound up by the provocative dance of DJ; as a 'rebel', DJ interweaves the language of love and affection with that of desire and passion. Much in the same way, in the song-and-dance sequence 'Khalbali Hai Khalbali' - 'there is commotion' - DJ is dancing with his friends while Sue watches them with a camera in her hand. Just a moment later, when Sue joins in the collective dance, DJ pulls her close to his body and, after a few slow movements and eye contact, they end up kissing, suspended in a heterotopic moment while the rest of their friends continue dancing unconcerned.

This second song-and-dance sequence, 'Khalbali Hai Khalbali', is composed of images of the college friends intercalated with images of their rebellious alter egos during their struggle for freedom. Sue and DJ's kiss and passionate defiance of convention rebelliously challenge the social norms of a traditional society, where firangiyon are often depicted negatively (Harris). The repertoire of gestures is enriched to include the explicit expression of sexual desire that not only involves lascivious glances but also draws on an evolving vocabulary of movements: the composition of the dance exudes sensuality and mimics the rhythms of sexual intercourse. While Rang de Basanti began a process of rehabilitation of the firangi within the entire narrative of the film, both 'Khalbali' and 'Masti Ki Paathshala' song-and-dance sequences have built an exclusive space. DJ and Sue are allowed, where the 'taboo of interracial relationship is broached in strategies and subterfuges' (Joshi 41), to exist within the story and yet, at the same time, to be suspended, as if in a capsule, away from what is traditionally acceptable within the plot of the film. Song-anddance sequences constitute, in harmony with Foucault's heterotopia, the space where an individual whose characterisation is deviant or divergent from the main context is placed within the story, in order to achieve a representation of a balanced and normalised society. 
Song-and-dance sequences in Love Aaj Kal and Rang de Basanti, the most recent films discussed in this article, have built a window of opportunity to rehabilitate firangiyon. Jo is allowed to exist within the story, but more than this her entrance in the film is accompanied by the song-and-dance "Twist", which evokes the moral abandonment and rebellion of the 1960s, providing a nostalgic and legitimised representation of firangiyon. The firangi Sue, on the other hand, goes one step further in that she is presented as a decent, generous and fair individual who is able to integrate into aspects of local society, at least until the film's final act, which denies her a happy ending in accordance with the ethics of Indian films of the past. The degree of Sue's acceptability within the narrative is higher than her firangi forebears. Sue presents the image of a positive girl; she speaks Hindi, is accepted by DJ's mother, is ashamed of her colonial history and seeks redemption through her grandfather's diary. In the song 'Masti Ki Paathshala', Sue is portrayed timidly clapping her hands, while at the beginning of 'Khalbali hai Khalbali', she is seen sitting on the floor watching her friends as they dance, swaying to the beat of the music in a way that is acceptable to traditional Indian standards. These sequences form a heterotopic moment - of detachment and suspension distinct from the main narrative of the text in which foreignness is often rejected. In spite of hinting at the acceptance of the firangi within the narrative, Sue and DJ are only able to live their romance within song-and-dance sequences. Hence, although they have been allowed into the plot, the firangi still suffer from a limited sense of integration; while song-and-dance sequences have constructed a habitat for their existence, they have not entirely removed the strictures of the past.

The role that song-and-dance sequences have played in depicting and defining the presence of foreign bodies and more broadly foreignness in popular Hindi cinema has changed considerably over time. From being modes of presenting a negative character or extraneous and alien presences within the filmic text, to exploring the modern diametric 
opposite of the traditional Hindi woman, song-and-dance sequences have facilitated the formation of patterns of representation of foreignness in popular Hindi cinema. Such models have seen the application of the mechanism of suspension from the narrative and from the filmic context, and the generation of specific portrayals of the firangi. While looking at Helen enabled us to think about a series of traits belonging to the firangi (which is not necessarily the gori), Sue and Jo have uncovered a depiction of the firangi that still connects with some level of transgression and otherness, of acceptance and rejection, of openness and closeness from and to the main narrative of the film.

\section{Conclusion}

Looking back at Foucault's heterotopic spaces, song-and-dance sequences can be read as a system that opens and closes the connection with the whole narrative - the Foucaultian surrounding - of the film within which the image of the firangi is constructed. These moments of interruption created since the beginning of the 1950s and 1960s an imaginary order, constructing a system of crisis with the main narrative of the film, which underlines the mere existence of firangi romance and social acceptability essentially within song-and-dance sequences.

These moments of the narrative were able to temporarily fix what was socially unacceptable. Song-and-dance sequences as heterotopic spaces within the narrative enable foreign bodies to be articulated, deferring their social value in favour of a more liberated approach. Song-and-dance sequences are germinal moments able to resolve, within the film, the unresolvable issue of foreignness as firangi bodies by defining their role in the film and the space they can occupy in the story. While Gopalan describes song-and-dance sequences as 'delaying the development of the plot, distracting us from the other scene of the narrative through spatial and temporal disjunction and bearing an integral part of the plot' (19), this article has taken a different approach. These sequences are not only moments of suspension 
in the development of the main narrative, but are also generative spaces in which the multiple possibilities of firangi representation can be unfurled.

Bollywood song-and-dance sequences house the tension between the inner and outer scenarios of modernity that the main narrative is unable to accommodate, thus becoming spaces of crisis; specific traits of foreignness are coded within the main text and given expression within song and dance, as 'joyous moments of cultural approval' (Sen 89). More than being a fundamental aspect of the narrative of Bollywood cinema, song-and-dance sequences have acted as moments of mediation and social 're-negotiation' of what is appropriate and what is not within the society. In this regard, the example of Helen is emblematic; she was a foreign body exploited for voyeuristic pleasure, without playing significant roles in the films, and yet the song-and-dance sequences in which Helen appeared were moments of decodification and permission for a certain identity to be performed and accepted. In these roles, we see a further development of this trend mentioned in the character of Jo, who enters the plot of the film from the dark space of a night club (codified as an alien and foreign place in the 1950s and 1960s where firangi could exist) to love Jai and perform the ritual of foreignness by a nostalgic dance of rebellion. Sue in Rang de Basanti represents another evolution in the language of foreignness; she is allowed into the story to unfold 'historical' redemption. Her performance within 'Masti Ki Paathshala' and 'Khalbali' permit the protagonist to passionately love DJ; however, it should be added that the story of Sue and DJ takes place within the frame of the socially 'secure' space of the university, where complicity dominates the relationship of the group of friends in the story. To conclude, in the films of the 1960s, firangi were embedded in alien performances, meaning a complete separation from the plot and with song-and-dance sequences acquiring the status of 'double interruptions' - from the narrative and from what is acceptable. In more recent films, while the plot has accommodated firangi within the story, presenting a reformed portrayal of the 
foreigner that is now permitted but not integrated into the plot, song-and-dance sequences remain reminders of their firanginess. The affirmation of this status, at spatial, temporal and representational levels, has enabled these musical interruptions to the story to become places of Foucaultian heterotopia - of possibility - for the cultural relocation of foreignness in popular Hindi cinema.

\section{Acknowledgement}

I would like to express my deepest gratitude to the organisers of the symposium "The Evolution of Song and Dance in Hindi cinema" for inviting me to be part of this event at Sonoma State University in 2017. I am also indebted to my colleagues at the symposium for their insightful comments on improving my manuscript. I would also like to thank Anugyan Nag for his encouragement and intellectual stimuli. My profound gratitude goes to Professor Justin Smith and Dr Matthew Jones for their invaluable support and advice in polishing this manuscript, and last but not least, a special thanks to the Cinema and Television History (CATH) research centre at De Montfort University, for funding my trip to the USA and supporting my research in this area.

\section{Notes}

1. The use of the word firangi in this article links to the work of Jonathan Gil Harris (2015). He traces the history of the term firangi, highlighting that the word originates from the French franc, which later turned into the Arabic ferenji before reaching its current avatar firangi. This word, Harries explains, broadly meant anyone who came from a Christian country, and it is often used in a derogatory manner. In this light, the terms firangi and firanginess in this article are used to expose cultural implications of foreign bodies that express pejorative perceptions of social status.

2. The term Bollywood has been well known for a long time; although it has been used in a broad sense for decades as a generic term to describe the commercial Hindi film industry, it is now also a branding term that represents popular artistic productions from India. I limit my usage of the term to refer to the post-1990s popular Hindi cinema industry.

3. The premise behind the development of this theme - the spaces of song-and-dance sequences as being capable of constructing an image of foreignness in Indian cinema - has its origins in my personal experience as a film scholar working on the impact of Bollywood in Italy (Acciari, 'Indo-Italian Screens and the Aesthetic of 
Emotions'). Back in 2007, I spent an extensive period of time in Rome, conducting fieldwork and extended interviews alongside participant observation of South Asian communities, in order to gather data regarding the settlement, migration history and film-going practices of these communities. I took part in a local dance-group and attempted a few Bollywood steps through the Apsaras Dance group, led by Italian Valentina Manduchi, a Roman dancer who found, through her school, the means to travel to India to both continue studying and establish working contacts with the popular Hindi cinema industry.

4. The translation of the song is not a word-for-word transliteration but rather gives its gist.

5. The translation of the song is not a word-for-word transliteration but rather gives its gist.

\section{References}

Acciari, Monia. 'Indo-Italian Screens and the Aesthetic of Emotions.' PhD thesis. University of Manchester, 2011. Print.

— . 'Theorizing Liminal Cinema: Unsettling the Transnational Spaces of Italian Indian CoProductions.' Journal of Italian Cinema and Media Studies 4.3 (2016): 387-402. Print. Beaster-Jones, Jayson. Bollywood Sounds. The Cosmopolitan Mediations of Hindi Film Song. New York: Oxford University Press, 2015. Print.

Devasundaram, Ashvin Immanuel. India's New Independent Cinema: Rise of the Hybrid. London: Routledge, 2017. Print.

Foucault, Michael. 'Of Other Spaces.' The Visual Culture Reader. Ed. Nicholas Mirzoff.

Second. London: Routledge, 2002. 22-27. Print.

—. The Order of Things. $1^{\text {st }}$ ed. London: Routledge, 1989. Print.

Foucault, Michael, and Jay Miskowiec. 'Of Other Spaces (Review).' Diacritics 16.1 (1986): 22-27. Print.

Gehlawat, Ajay. 'The Gori in the Story: The Shifting Dynamics of Whiteness in Bollywood.' Twenty-First Century Bollywood. New York: Routledge, 2015. 66-87. Print. Gopal, Sangita, and Sujata Moorti. 'Introduction'. Global Bollywood. Ed. Sangita Gopal and 
Sujata Moorti. Minneapolis: University of Minnesota Press, 2008. 1-60. Print.

Gopalan, Lalitha. Cinema of Interruptions. London: Oxford University Press, 2002. Print.

Gowariker, Ashutosh. Lagaan: Once Upon a Time in India. 2001. Film.

Harris, Gil Jonathan. The First Firangis: Remarkable Stories of Heroes, Healears,

Charlatans, Cortesans and other foregners who became Indian.Delhi: Aleph Book Company, 2015. Print.

Jenkins, Henry, and Sangita Shresthova. 'Up, Up, and Away! The Power and Potential of Fan Activism.' Trasformative Works and Culture 10.2 (2012),

http://journal.transformativeworks.org/index.php/twc/article/view/435/305 (accessed June 2017)

Joshi, A. Sarah. 'Transgressing the moral Universe Bollywood and the Terrain of the Representable'. Bollywood and its other(s): Towards New Configurations, Ed. Vikrant Kishore, Amit Sarwal and Parichay Patra. Basingstoke: Palgrave Mcmillian, 2014. 4154. Print.

Kishore, Vikrant. 'Bollywood Vamps and Vixens: Representations of the Negative Women Characters in Bollywood Films.' Transgressive Womanhood: Investigating Vamps, Witches, Whores, Serial Killers and Monsters. Ed. Manon Hedenborg-White and Bridget Sandhoff. Oxford, UK: Inter-Disciplinary Press, 2014. 141-152. Print.

Kishore, Vikrant, Amit Savwal and Parichay Patra. Bollywood and its Other(s): Towards New Configurations. New York: Palgrave MacMillan, 2016. Print.

Knowles, Mark. Tap Roots: The Early History of Tap Dancing. London: McFarland, 2002. Print.

Lal, Vinay. 'The Impossibility of the Outsiders in Modern Hindi Films.' The Secret Politics of Our Desires: Innocence, Culpability and Indian Popular Cinema. Ed. Ashis Nandy. London: Zed Books, 1998. 228-259. Print. 
Mishra, S. 'Negotiating Female Sexuality.' Belly Dance Around the World. Ed. McDonald, C. and Sellers-Young, B. Jefferson, NC: McFarland and Company. 2013. 181-196. Print.

Pinto, Jerry. Helen: The Life and Time of a H-Bomb. London: Penguin, 2006. Print.

Sen, Biswarup. 'The Sounds of Modernity: The Evolution of Bollywood Film Song.' Global Bollywood: Travels of Hindi Song and Dance. Ed. Sangita Gopal and Sujata Moorti. Minneapolis: University of Minnesota Press, 2008. 85-104. Print.

Shresthova, Sangita. Is It All About Hips? Around the World with Bollywood Dance. London: Sage, 2011. Print.

Thomas, Rosie, 'Not Quite (Pearl) White: Fearless Nadia, Queen of the Stunts.' Bollyworld: Popular Indian Cinema through a Transnational Lens. Ed. Raminder Kaur and Ajay J. Sinha. London: Sage, 2005. 35-69. Print.

Vasudevan, Ravi. 'Bombay and Its Public.' Journal of Arts and Ideas 1.29 (1996): 45-66. Print.

\section{Filmography}

Salaam-E-Ishq. Dir. Nikkhil Advani. Orion Pictures, 2007. Film.

Love Aaj Kal. Dir. Imtiaz Ali. Eros International, 2009. Film.

Kites. Dir. Anurag Basu. Reliance Entertainment, 2010. Film.

Rang De Basanti [Colour It Yellow]. Dir. Rakeysh Omprakash Mehra. UTV Motion Pictures, 2006. Film.

Gumnaam [The Unknown]. Raja Nawathe. 1965. Film. Howrah Bridge. Shakti Samanta. 1958. Film. 